\title{
Rice-husk-based superplasticizer to increase performance of fly ash geopolymer concrete
}

Ramesh Kumar Chouhan MTech

Principal Technical Officer, Materials for Radiation Shielding and Cement Free Concrete Division, Council of Scientific and Industrial

Research-Advanced Materials and Processes Research Institute, Bhopal, India (corresponding author: rkchouhan33@yahoo.com)

Manish Mudgal PhD

Principal Scientist, Materials for Radiation Shielding and Cement Free

Concrete Division, Council of Scientific and Industrial Research-Advanced

Materials and Processes Research Institute, Bhopal, India

\begin{abstract}
Abhishek Bisarya MTech
Junior Research Fellow, Materials for Radiation Shielding and Cement Free Concrete Division, Council of Scientific and Industrial Research-Advanced Materials and Processes Research Institute, Bhopal, India

Avanish Kumar Srivastava PhD

Director, Council of Scientific and Industrial Research-Advanced Materials and Processes Research Institute, Bhopal, India
\end{abstract}

Workability is a major drawback of fly-ash-based geopolymers due to high viscosity. In this research, a new type of superplasticizer is developed to overcome this workability issue. Due to the high viscosity of geopolymeric binder structures, none of conventional superplasticizers was found effective in maintaining the viscosity of the mixture. The novel hybrid superplasticizer was developed by utilizing agrowaste - that is, rice husk - and an alkaline activator. Characterization studies [by X-ray diffraction, Fourier transform infrared spectroscopy and field emission scanning electron microscope] of the material indicated that the amorphous silica from rice husk reacts with the alkaline activator - that is, sodium hydroxide - and results in the in situ synthesis of sodium silicate and lignin. The developed superplasticizer was used in different percentages in fly-ash-based geopolymeric systems to study its engineering properties. The workability of the fresh geopolymer concrete was measured using the slump cone test method as per IS 1199-1959, while the compressive strength was evaluated as per IS 516-1959, and it is reported that the workability of the geopolymer concrete was improved significantly compared to that of conventional geopolymeric systems. In the present work, an attempt has also been made to establish a working mechanism for the developed superplasticizer with geopolymeric systems, which indicated its compatibility with [-Si-O-Al-O-] networks.

\section{Introduction}

An emerging new class of binder for making concrete mixtures which not only is an alternative to ordinary portland cement but also possesses environmental sustainability characteristics in terms of usage of waste materials and less production of greenhouse gases is 'geopolymer concrete'. ${ }^{1-3}$ Introduced by Davidovits, geopolymers are inorganic aluminosilicate autopolycondensed polymers prepared by reacting any glassy silicoaluminous source with highly alkaline activator solution. ${ }^{4}$ The two most commonly used alkaline activators for this process are sodium hydroxide $(\mathrm{NaOH})$ and sodium silicate $\left(\mathrm{Na}_{2} \mathrm{SiO}_{3}\right)$, the hydroxyl combination of which results in leaching of amorphous silicon $(\mathrm{Si})$ /aluminum (Al) from the source material and ultimately transforming into a three-dimensional highly cross-linked geopolymeric framework. ${ }^{3,4}$ The whole process may be assisted by thermal curing followed by drying. Generally, geopolymers are believed to possess excellent mechanical strength and heat- and fire-resistant properties along with an appreciable durability property.

Concrete workability is a very crucial factor and known to affect the compatibility, consistency, pumpability and flowability of a concrete mixture. The workability of concrete refers to the attempt needed to manipulate a freshly prepared concrete mixture with minimum loss of homogeneity. ${ }^{1,2}$ One of the major issues encountered with fly-ash-based geopolymers is their workability during on-site practical application. Geopolymeric material is prone to settling fast, rendering highly viscous unmanageable concrete mixtures. Dissimilar to conventional concrete systems, geopolymeric concrete settles rapidly and causes several workability problems during on-site application. However, the problem can be rectified to some extent with the addition of available commercial superplasticizers - namely, naphthalene, modified polycarboxylates, lignosulfonates and so on, which are organic in nature and somewhat show compatibility with geopolymeric $\mathrm{Si}-\mathrm{O}-\mathrm{Al}-\mathrm{O}$ networks. In a study, researchers studied the effect of different commercial superplasticizers such as naphthalene, melamine and modified polycarboxylates on the workability of class F fly ash geopolymer paste and the effect of the addition of these commercial superplasticizers on the resulting mechanical strength. They reported that the effect of workability and strength of the geopolymer depends on the type of the superplasticizer used. ${ }^{3}$ Researchers also reported negative effects of the addition of a superplasticizer to the concrete mixture in terms of compressive strength as low strengths were reported, which may be due to the instability of these superplasticizers in highly alkaline activator solutions. ${ }^{5,6}$ The $\mathrm{pH}$ of such alkaline solution is equal to $13 \cdot 36$, causing structural changes and rearrangements in organic groups, which results in the loss of their plasticizing characteristics. ${ }^{7}$ 
Viewing the importance of the issue, this study reports the development of a novel superplasticizer in the laboratory using agrowaste rice husk. In this study, rise husk (as such) was boiled with sodium hydroxide solution continuously for a specific duration and the resulting novel viscous mixture is termed as 'mother liquor' (ML), which acts as a novel superplasticizer for geopolymer concrete mixtures. This ML is further used to prepare fly-ash-based geopolymeric concrete as an alkaline activator, and the effect of the addition of different percentages of ML on strength and workability is reported. The objective of this study is to analyze experimentally the novel superplasticizer on the basis of characterization with the help of X-ray diffraction (XRD), Fourier transform infrared spectroscopy (FTIR) and scanning electron microscopy (SEM) and then to investigate its effects on geopolymeric concrete strength by using the compressive strength test and on flow behavior by using the traditional slump cone test. This investigation reports the development and preparation process of the novel superplasticizer in the laboratory and its minimum optimum percentage which is required for maximum slump and strength.

\section{Methods and materials}

\subsection{Materials}

Class F fly ash from the Satpura Thermal Power Plant, Sarni, Madhya Pradesh, India, was used as the main aluminosilicate precursor. The chemical composition and loss on ignition (LOI) of the fly ash are presented in Table 1, which indicates that the major mineralogical proportion of it is attributed to silicon dioxide $\left(\mathrm{SiO}_{2}\right)$ and aluminum oxide $\left(\mathrm{Al}_{2} \mathrm{O}_{3}\right)$. The physical property evaluation of fly ash was carried out at the Council of Scientific and Industrial Research-Advanced Materials and Processes Research Institute (CSIR-Ampri), and the results are presented in Table 2.

An alkaline activator with a concentration of $12.5 \mathrm{M}$ was used in this study. Locally available basaltic coarse aggregates, a combination of two different sizes, $40 \% 20 \mathrm{~mm}$ and $60 \% 10 \mathrm{~mm}$, with a fineness modulus of 6.3 and locally available river sand that is, fine aggregate - with a fineness modulus of 2.6 were used, same as that of the cement concrete mixture. Mixtures of laboratory-reagent-grade sodium hydroxide and sodium metasilicate of $99 \%$ purity were used as conventional alkaline

Table 1. Chemical composition of fly ash in percentage

$\begin{array}{lc}\text { Component } & \text { Percentage: \% } \\ \text { Silicon dioxide } & 62 \cdot 12 \\ \text { Aluminum oxide } & 21 \cdot 30 \\ \text { Iron (III) oxide }\left(\mathrm{Fe}_{2} \mathrm{O}_{3}\right) & 5 \cdot 55 \\ \text { Titanium dioxide }\left(\mathrm{TiO}_{2}\right) & 1 \cdot 38 \\ \text { Magnesium oxide }(\mathrm{MgO}) & 1 \cdot 58 \\ \text { Calcium oxide }(\mathrm{CaO}) & 0 \cdot 53 \\ \text { Potassium oxide }\left(\mathrm{K}_{2} \mathrm{O}\right) & 4 \cdot 24 \\ \text { LOI } & 3 \cdot 30\end{array}$

Table 2. Physical properties of fly ash

$\begin{array}{lc}\text { Blaine's specific surface area } & 360 \mathrm{~m}^{2} / \mathrm{kg} \\ \text { Fineness: \% retained on } 45 \mu \mathrm{m} \text { sieve } & 28 \\ \text { Specific gravity } & 2 \cdot 1\end{array}$

activators for this study. Locally available rice husk was used for the preparation of the ML superplasticizer.

The laboratory-optimized weight percentages of fly ash $(15 \cdot 3 \%)$, sodium hydroxide $(1.95 \%)$, sodium metasilicate $(0.95 \%)$, coarse aggregate $(51 \cdot 20 \%)$, fine aggregate $(25 \cdot 6 \%)$ and water $\left(\mathrm{H}_{2} \mathrm{O}\right)$ $(3 \cdot 8 \%)$ were used in this study. In this study, the basic composition of the geopolymeric concrete mixture such as the sodium silicate/ sodium hydroxide ratio, silicon/aluminum ratio and molarity of the mixture was kept constant so as to evaluate the effect of the addition of different percentages of the ML superplasticizer to the mixture. A total of five samples were prepared using specified compositions with one control sample to study the effect of the addition of the ML superplasticizer on the slump and strength of concrete. The details are presented in Table 3.

\subsection{Preparation of novel ML superplasticizer}

To prepare the ML superplasticizer in the laboratory, the method involved boiling of rice husk with highly alkaline solution made by dissolving sodium hydroxide in water. The procedure started with dissolving $500 \mathrm{~g}$ sodium hydroxide into $1000 \mathrm{ml}$ of water $(12 \cdot 5 \mathrm{M})$ and then adding $100 \mathrm{~g}$ of rice husk to this solution. The container was placed on a low-flame burner, and the complete mixture was boiled continuously for $1 \mathrm{~h}$. The rice husk contained organic constituents - namely, cellulose, hemicellulose and lignin - and inorganic silica accumulated on the outer surface of the epidermis of the rice husk. During the preparation of the ML superplasticizer, high-temperature alkaline hydrolysis of organic constituents present in rice husk took place and some amount of inorganic silica leached into the solution from the rice husk. The resulting dark-brown-colored solution was then filtered and collected in an airtight glass bottle. This superplasticizer is specially developed for geopolymer systems as the commercially available superplasticizer results in a decrease in the engineering properties of geopolymers. The flow chart, raw materials and procedure for this novel process are depicted in Figure 1. The

Table 3. Details of various mixtures prepared using different percentages of ML superplasticizer

$\begin{array}{lccc}\begin{array}{l}\text { Sample } \\ \text { code }\end{array} & \begin{array}{c}\text { Sodium } \\ \text { silicate/sodium } \\ \text { hydroxide } \\ \text { ratio }\end{array} & \begin{array}{c}\text { Percentage of } \\ \text { superplasticizer } \\ \text { (with respect to } \\ \text { fly ash): \% }\end{array} & \begin{array}{c}\text { Molarity of } \\ \text { mixture: M }\end{array} \\ \text { ML0.0 } & 0.5 & 0.00 & 12.5 \\ \text { ML0.25 } & 0.5 & 0.25 & 12.5 \\ \text { ML0.50 } & 0.5 & 0.50 & 12.5 \\ \text { ML0.75 } & 0.5 & 0.75 & 12.5 \\ \text { ML1.0 } & 0.5 & 1.00 & 12.5\end{array}$




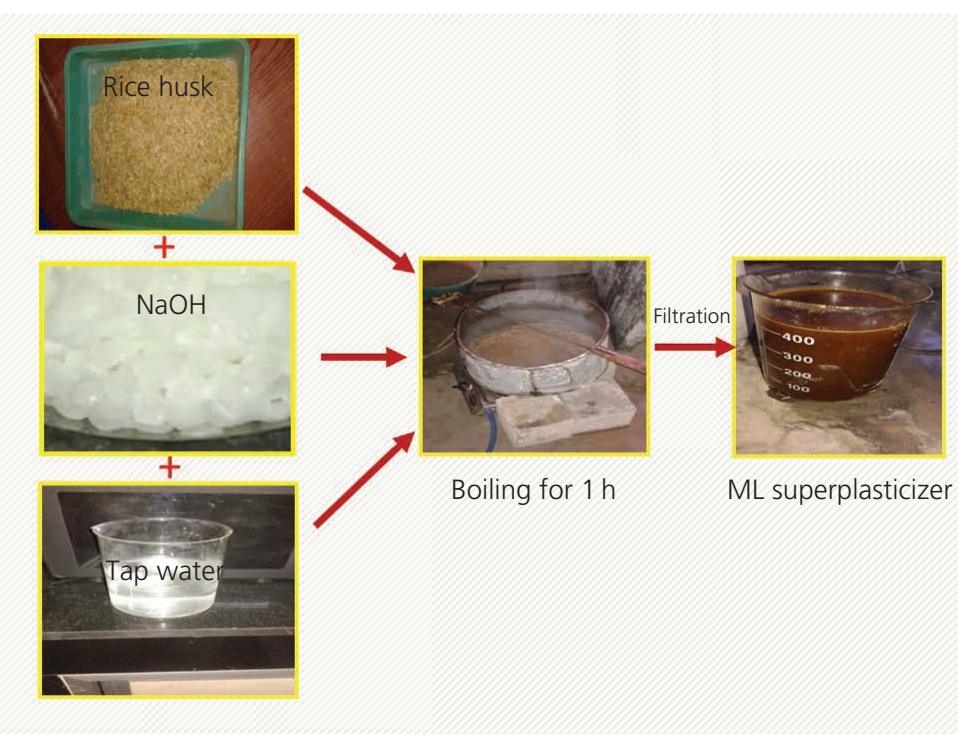

Figure 1. Method for preparation of novel ML superplasticizer in laboratory

rice-husk-based ML superplasticizer is then subjected to characterization studies, including XRD, FTIR and SEM, to study the formation of different mineral phases, chemical bonding and microstructure, respectively.

\subsection{Development of fly-ash-based geopolymer concrete}

To investigate the effect of different percentages of the ML superplasticizer on the workability and strength of geopolymeric concrete, the control mix was prepared using sodium hydroxide and sodium silicate as the alkaline activator solution. Sodium hydroxide and sodium silicate were dissolved in water, and the molarity of the solution was maintained at $12.5 \mathrm{M}$. A cylindrical cement concrete mixer was used to mix fine and course aggregates for $3-5 \mathrm{~min}$. Fly ash is then added to the mixer, and proper mixing was allowed for about $5 \mathrm{~min}$. Following the procedure, a homogenous dry mix was obtained and then the activator solution was added to initiate geopolymerization reactions with continuous rotation of the mixer for about $15 \mathrm{~min}$. The developed fly-ash-based geopolymeric concrete was the control sample (without ML superplasticizer). Afterwards four batches were prepared following the same procedure with the addition of four different percentages of the ML superplasticizer $(0 \cdot 25,0 \cdot 50,0 \cdot 75$ and $1 \cdot 0 \%)$. Each composition was then further evaluated for slump and compressive strength.

\subsection{Slump cone test}

The slump cone test, also known as the spread flow test, was conducted according to IS $1199-1959 .{ }^{8}$ The height of the slump cone was $30 \mathrm{~cm}$, and its top and bottom diameters were 10 and $20 \mathrm{~cm}$, respectively. Before starting the test, the internal surface of the slump cone was cleaned properly and applied with a thin layer of oil. The cone was then placed on a smooth, horizontal, rigid and non-absorbent surface and filled with freshly mixed geopolymer concrete in four layers, each layer tamped 25 times, and strokes were distributed evenly over the cross-section. At the end, the slump cone was removed immediately by raising it slowly vertically in the upward direction. The difference in level between the height of the slump cone and that of the highest point of the subsided geopolymer concrete was measured, and the difference in height was reported in millimeters.

\subsection{Compressive strength evaluation}

To measure the compressive strengths of all five concrete compositions, cubes of size $15 \mathrm{~cm} \times 15 \mathrm{~cm} \times 15 \mathrm{~cm}$ were cast and compacted on a vibration table, oven-cured at $60^{\circ} \mathrm{C}$ for $48 \mathrm{~h}$, demolded after $24 \mathrm{~h}$ of curing, kept again for the next $24 \mathrm{~h}$ so that heat reached properly all faces of the cubes and then left at ambient temperature - that is, after $48 \mathrm{~h}$ of oven curing. The cubes were tested as per IS 516-1959, ${ }^{9}$ in which three cubes were tested at different ages and the average was taken as the compressive strength. Testing of compressive strength was performed on a Heico compressive strength testing machine at 3 , 7,14 and $28 \mathrm{~d}$, and the results were reported in megapascals.

\subsection{Characterization of ML superplasticizer}

The ML superplasticizer was characterized by XRD using a Rigaku X-ray diffractometer at CSIR-Ampri with copper $(\mathrm{Cu}) \mathrm{K} \alpha$ radiation to identify the various different phases present in the ML superplasticizer. The XRD intensity was recorded as a function of Bragg's $2 \theta$ in the angular range of $5-70^{\circ}$. FTIR was performed between 500 and $4000 \mathrm{~cm}^{-1}$ to determine the functional group present in the ML superplasticizer sample by using a Bruker Alpha FTIR spectrometer. SEM micrographs of the ML superplasticizer were obtained using a Jeol Jem-35-CF scanning electron microscope at CSIR-Ampri. Before 
microstructural analysis, the samples were mounted on aluminum stubs by using carbon tape and then coated with a thin layer of gold to prevent charging before the observation.

\section{Results and discussion}

\subsection{Workability}

Normally, fresh geopolymeric concrete has been reported to be less workable due to its highly viscous nature and strong cohesion between particles. It becomes stiff in a short duration and thus has a short initial setting time. ${ }^{10,11}$ Several studies in the literature are available in which numerous trail mixes were prepared and tested for different parameters to study the factors affecting properties of either fresh or hardened geopolymer concrete. ${ }^{11-13}$ Some studies reported that the workability of geopolymer depends on the concentration of alkaline activators which donate the viscous nature to the concrete mixes. ${ }^{5}$ In the present study, the workability of fresh geopolymer concrete was affected by the amount of the ML superplasticizer used. The comparison of workabilities of five different geopolymeric concrete mixes is presented in Figure 2. From Figure 2, it is very clear that a higher slump gain was reported in samples ML0.25, ML0.5, ML0.75 and ML1.0 compared with the control sample. The highest slump gain was for ML1·0, which indicated that the higher the amount of the superplasticizer is the higher the flowability of the geopolymeric concrete will be.

The flows of slump for ML0.25, ML0.50, ML0.75 and ML1.0 were $80,150,175$ and $200 \mathrm{~mm}$, respectively. It can be noted that the addition of the ML superplasticizer to the geopolymer concrete mixture increased the slump value by $100 \%$ compared with the control one. Similarly, the addition of a higher dosage of the ML superplasticizer in samples ML0.25, ML0.50, ML0.75 and ML1.0 increased the slump value by $275,337 \cdot 5$ and $400 \%$ compared to the control (ML0.0) and by $87 \cdot 5,16 \cdot 6$ and $14 \cdot 2 \%$, respectively, compared with the sample with the next lower dosage. Thus, the workability of geopolymer concrete showed increasing trends with respect to increasing dosage of the ML superplasticizer. The lowest

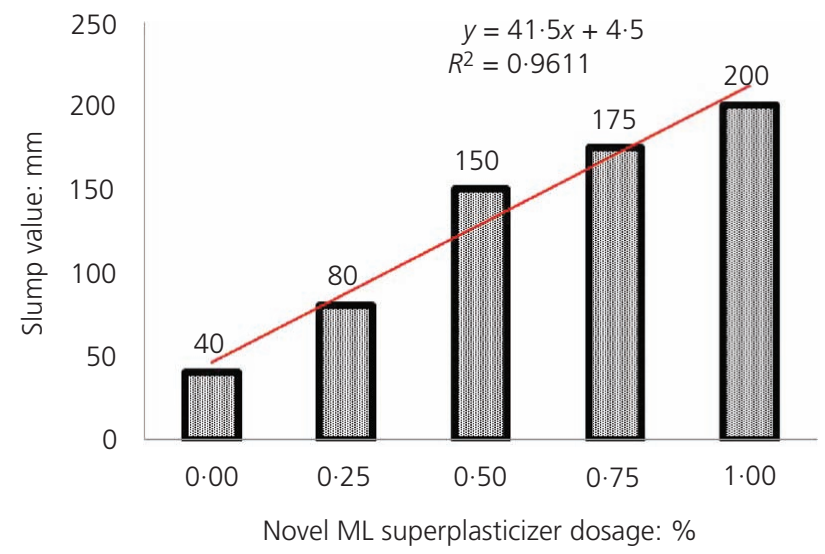

Figure 2. Variation in slump gain by using different dosages of ML superplasticizer for geopolymer concrete slump value was reported for ML0.25, whereas the highest slump value was reported for ML1 0 , and the slump values of all samples were found to be increased effectively to a greater extent compared to that of the control sample. Further, through visual inspections, it was noted that in the case of ML0.0, where no ML superplasticizer was added, the mixture was too viscous to work with at room temperature and had a very stiff flow behavior compared to the other four. Easy flowability and drops in viscosity were reported as the dosage of the ML superplasticizer was increased sample by sample. The slump test results clearly indicated that the novel ML superplasticizer was effective in enhancing the flowability of the geopolymer concrete to a considerable level as no segregation and bleeding was observed during mixing and testing of the geopolymer concrete. In fact, the addition of the ML superplasticizer provided easy mixing, good compaction and excellent finishing to geopolymer concrete mixes. Similar test results were obtained by other researchers with fly-ash-based geopolymer concrete mixtures. ${ }^{14-16}$

\subsection{Compressive strength}

Since the main engineering properties of concrete could be correlated with compressive strength, the compressive strength test is therefore used as an indicator to decide the relative functions, other mechanical properties and applications of concrete. It is an important property most commonly used to describe any concrete system. Figure 3 indicates the compressive strength values in megapascals for five concrete samples at different curing periods. Average values of three cubes were used to describe the compressive strength of samples on the graph. According to Figure 3, results indicated that the $28 \mathrm{~d}$ compressive strength was highest for all samples, which were similar to results for the conventional cement concrete system. The graph shows that the development of $28 \mathrm{~d}$ strength in all compositions was affected by the addition of the superplasticizer. The strength development showed a downward trend beyond the ML superplasticizer dosage of $0 \cdot 5 \%$ and continued to decrease up to a dosage of $1 \cdot 0 \%$ ML superplasticizer.

As shown in Figure 3, there was a $65 \%$ strength decrease in the case of sample ML0.75 and $74 \%$ strength reduction for sample ML1.0 compared to sample ML0.5. The effect of the ML superplasticizer on the concrete strength appears to be more pronounced in the case of ML0.5, where the strength reported was highest - that is, $58 \cdot 1 \mathrm{MPa}-$ at $28 \mathrm{~d}$ curing. Thus, further addition of the ML superplasticizer to the geopolymer concrete resulted in strength reduction, which may be attributed to the rise in $\mathrm{OH}^{-}$due to the extra addition of the ML superplasticizer, which altered the required water/sodium oxide $\left(\mathrm{Na}_{2} \mathrm{O}\right)$ ratio of the geopolymeric system, and hence a reduction in strength was reported. It should be noted that the addition of a higher amount of the ML superplasticizer may lead to disturbed water/sodium oxide and sodium oxide/aluminum oxide ratios, causing porosity in the structural framework, and an optimum dosage of a superplasticizer is therefore required to attain good flowability without compromising mechanical strength. As reported by other 


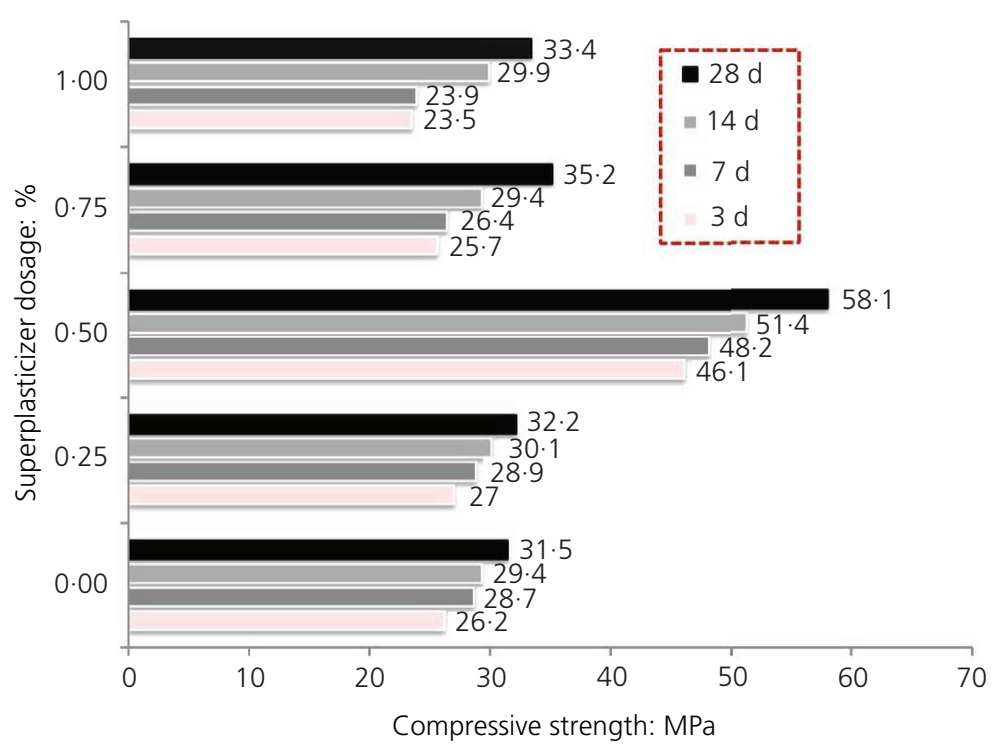

Figure 3. Compressive strength variation in geopolymer concrete by using different dosages of ML superplasticizer

researchers, the mechanical strength of a geopolymer shows a decreasing trend with respect to increasing dosage of the superplasticizer generally above $2 \% .{ }^{13}$ In the present study, even less amount of a superplasticizer is needed to attain significant concrete strength. Thus, it is concluded that in this study, the ML superplasticizer of $0.5 \%$ by weight of fly ash proved to be optimum for fly-ash-based geopolymer concrete.

\subsection{Characterization studies}

\subsubsection{Characterization of fly ash}

The XRD spectrum of fly ash is mainly composed of peaks corresponding to quartz, mullite and hematite with an amorphous broad hump recorded from 5 to $20^{\circ} 2 \theta$. The XRD spectrum of only fly ash (see Figure 4(a)) indicates the presence of mineralogical phases and numerous peaks including silicon dioxide, aluminum oxide $\left(3 \mathrm{Al}_{2} \mathrm{O}_{3} \cdot \mathrm{SiO}_{2}\right)$ and iron (III) oxide as minor phases. The phase identification was performed using JCPDS software in the laboratory by comparing the corresponding
' $d$ ' values obtained with the standard. Figure 4(b) presents the microstructure of fly ash particles under SEM analysis, which indicates the presence of hollow smooth surface particles and some irregular and spherical particles and the availability of crystalline grains. The particle size of used fly ash varied from 10 to $45 \mu \mathrm{m}$.

\subsubsection{Characterization of ML superplasticizer 3.3.2.1 XRD ANALYSIS}

The XRD spectrum of the ML superplasticizer is shown in Figure 5 , which indicates the presence of a number of peaks with varying intensities. The spectrum shows a broad non-symmetrical hump between 5 and $17^{\circ} 2 \theta$, indicating the presence of non-crystalline phases and the vitreous nature of the ML superplasticizer. In fact, the vitreous nature actively participated in the geopolymerization reaction and resulted in good mechanical strength of the geopolymeric concrete. The two major inorganic phases reported in the novel ML superplasticizer were sodium silicate $\left(\mathrm{Na}_{4} \mathrm{SiO}_{4}\right)$ and sodium hydroxide. Three minor organic phases originated due to

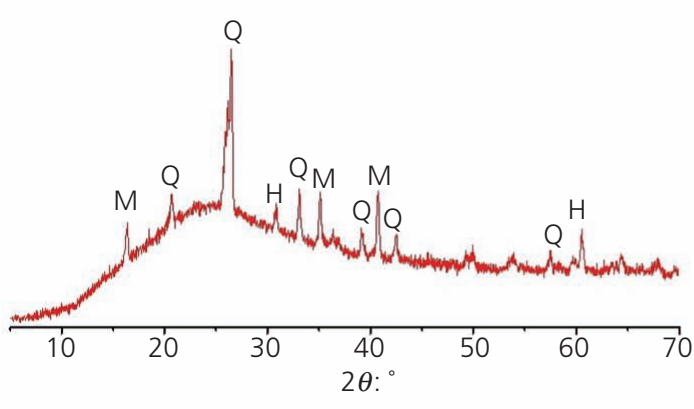

(a)

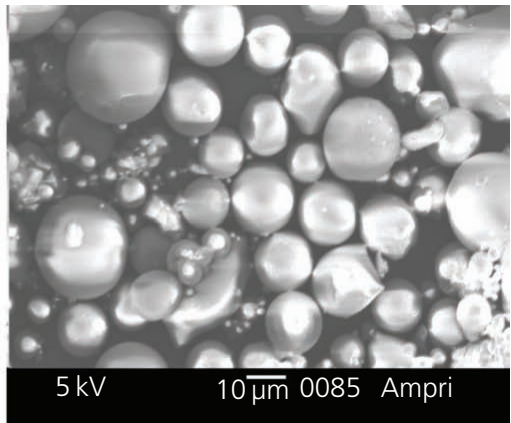

(b)

Figure 4. (a) XRD spectrum of fly ash; (b) microstructure of fly ash. Q, quartz, M, mullite; H, hematite 


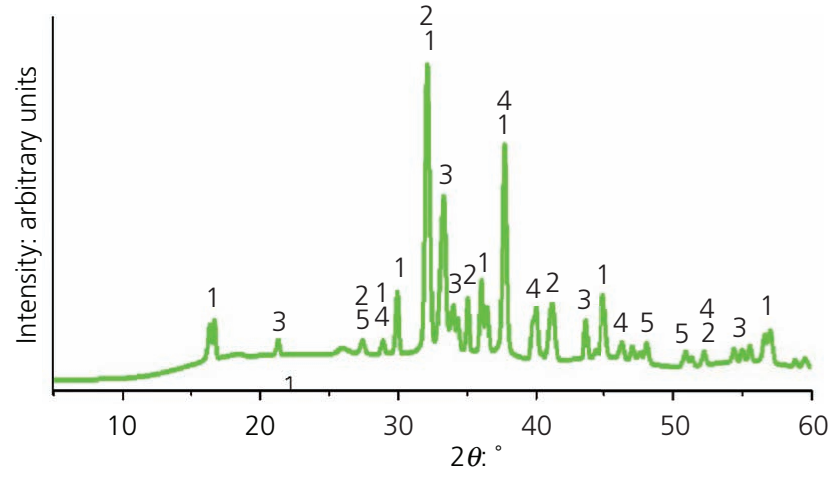

Figure 5. XRD spectrum of novel ML superplasticizer. 1, sodium hydroxide; 2 , sodium silicate; 3 , native cellulose; 4 , $\beta$-D-fructose; 5 , phenol

the action of alkali on rice husk, and these were native cellulose $\left(\left(\mathrm{C}_{6} \mathrm{H}_{12} \mathrm{O}_{6}\right)_{\mathrm{x}}\right), \beta$-D-fructose $\left(\mathrm{C}_{6} \mathrm{H}_{12} \mathrm{O}_{6}\right)$ and phenol $\left(\mathrm{C}_{6} \mathrm{H}_{6} \mathrm{O}\right)$.

The action of sodium hydroxide on the inorganic silica present on the outer surface of rice husk resulted in the in situ synthesis of sodium silicate, which provided an intense amorphous nature to the developed ML superplasticizer. It is to be noted that sodium silicate acts as a seeding agent for geopolymerization reactions ${ }^{2,17}$ and, in the present study, it was synthesized in situ by the continuous alkaline digestion of rice husk and thus promoted the degree of geopolymerization reactions during the addition of the ML superplasticizer to the concrete mixture. The plasticizing effects were contributed by organic phases in the ML superplasticizer namely, native cellulose, fructose and phenol. XRD peaks provided strong signals of crystalline cellulose in the ML superplasticizer sample, whereas the amorphous part of the cellulose structure is represented by a broad and less clear diffraction pattern (see Figure 5). The evolution of native cellulose in the ML superplasticizer directly indicated the action of alkali on rice husk during high-temperature alkaline digestion. ${ }^{18}$ The unburnt rice husk contained cellulose, hemicellulose and lignin as major organic fractions. The structural breakdown and rearrangement of hemicelluloses during alkaline digestion of rice husk resulted in the formation of some smaller-molecular-weight units of $\beta$-D-fructose and phenol, which was the alkaline hydrolysis product of lignin. Due to the complexity of the structures of hemicelluloses and lignin, it is difficult to envisage the complete transformations and rearrangements during alkaline digestion of rice husk, but XRD peaks of the resulting inorganic and organic fractions clearly indicated the action of sodium hydroxide on the rice husk inorganic silica and organic cellulose, hemicellulose and lignin to produce hydrolysis products such as $\beta$-D-fructose and phenol in the ML superplasticizer.

Furthermore, it is to be pointed out that the commercially available water-reducing organic plasticizers for cement concrete systems perform the function of dispersants into the mixture, where they provide electric repulsion of positive and negative charges and hence the charged cement grains tend to separate from each other to acquire good flowability. ${ }^{19,20}$ Although dissimilar to the conventional cement concrete system, the mechanism is quite different for geopolymers as the structural framework of geopolymers can form a neutral or anionic skeleton of silicon and aluminum hydroxides and the dispersing power of the superplasticizer is reduced to a lesser extent in this case. ${ }^{20,21}$ In the present study, no commercial superplasticizer is used but in fact the same function of an organic superplasticizer was performed by the organic fractions provided by rice husk as detected by XRD characterization of the ML superplasticizer. The functional groups of cellulose, phenol and $\beta$-D-fructose facilitate the dispersion of charged ions into the geopolymeric framework and hence resulted in the increased workability of the concrete mixture. However, for the sample ML0.5 (with a dosage of $0.5 \%$ ML superplasticizer), increased flowability as well as the highest compressive strength were obtained, which indicated that the $0.5 \%$ concentration of the ML superplasticizer with respect to fly ash is the optimal dose and can be used frequently for geopolymer concrete mixes.

\subsubsection{FTIR ANALYSIS}

FTIR characterization was employed to investigate the presence of different inorganic and organic bonds in the novel ML superplasticizer and the spectrum obtained is shown in Figure 6. Figure 6 illustrates the major absorbance band at the region between 500 and $3000 \mathrm{~cm}^{-1}$. The significant peaks which were observed at 616,705 and $777 \mathrm{~cm}^{-1}$ were attributed to $\mathrm{O}-\mathrm{Si}-\mathrm{O}$ and $\mathrm{Si-}-\mathrm{O}-\mathrm{Si}$ bending vibrations of in situ-synthesized inorganic silicate. Although the intensities of their bands were low compared to those of other bands, their presence confirmed the in situ formation of sodium silicate by the action of sodium hydroxide on inorganic silica from rice husk. On the other hand, one intensified band situated at $1428 \mathrm{~cm}^{-1}$ was a band characteristic of $\mathrm{O}-\mathrm{C}-\mathrm{O}$ stretching vibrations of sodium carbonate, which was believed to originate due to the action of sodium $(\mathrm{Na})$ with atmospheric carbonate. Its high intensity was an indication of the highly reactive nature of sodium to form

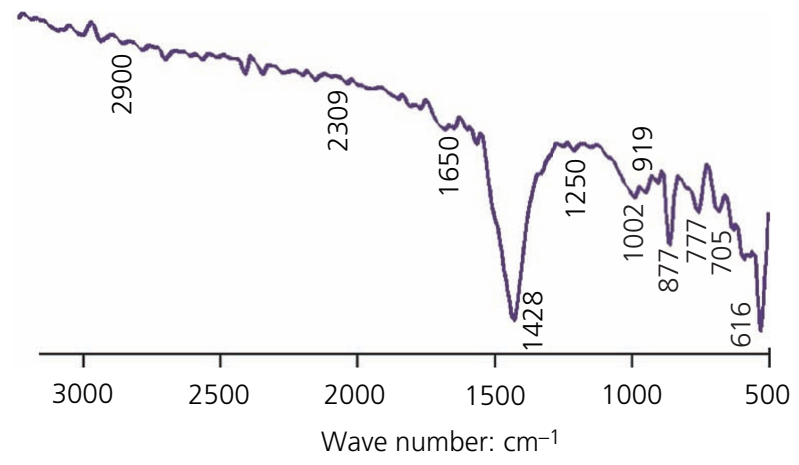

Figure 6. Different vibrational modes in FTIR region obtained for ML superplasticizer 
compounds such as sodium carbonate. ${ }^{22}$ The other small diffused bands at $919-1002$ and $1250 \mathrm{~cm}^{-1}$ corresponded to $\mathrm{Si}-\mathrm{O}$ stretching in silicate glasses and weak $\mathrm{C}-\mathrm{O}$ stretching in native cellulose, respectively. ${ }^{23,24}$

Some characteristic weak peaks in the ML superplasticizer spectrum at the frequency region of $1650 \mathrm{~cm}^{-1}$ were attributed to quadrant ring stretching in lignin and carbonyl stretching including $\mathrm{C}=\mathrm{O}$ stretching originating from organic fractions present in the ML superplasticizer, ${ }^{25,26}$ whereas small bands at 2309 and $2900 \mathrm{~cm}^{-1}$ were associated with $\delta \mathrm{CH}_{2}+\delta \mathrm{OCH}+$ $\delta \mathrm{CCH}$ and $-\mathrm{CH}$ stretching vibrations from fructose and native cellulose. $^{26}$ These results again confirmed the XRD results and indicated the formation of inorganic and organic compounds in the ML superplasticizer. Results of FTIR analysis demonstrated that the addition of the ML superplasticizer to the geopolymer concrete lowered the viscosity and increased the flow behavior of concrete (see Figure 2) as an effect of the presence of organic fractions in the ML superplasticizer imparted by alkaline digestion of rice husk

\subsubsection{ENERGY-DISPERSIVE X-RAY SPECTROMETRY AND MICROSTRUCTURAL ANALYSIS}

The energy-dispersive X-ray spectrometry (EDX) profile of the ML superplasticizer is presented in Figure 7, which indicates the presence of elements silicon, oxygen $(\mathrm{O})$, carbon $(\mathrm{C})$, aluminum and potassium $(\mathrm{K})$ at varying atomic weight percentages. The EDX profile predominantly contains the elements oxygen, $61 \cdot 2 \%$; sodium, 20.7\%; carbon, $9 \cdot 15 \%$; and silicon, $7 \cdot 90 \%$, and the rest are traces of aluminum and potassium. As can be seen from the spectrum, the majority weight percentage corresponds to oxygen, sodium and silicon, which is obvious due to the highly inorganic nature of the ML superplasticizer, whereas the presence of carbon indicates the participation of organic fractions from rice husk in the form of cellulose, phenol and $\beta$-D-fructose, which are the factors causing the good flow behavior of the geopolymer concrete. However, their weight percentages were low compared

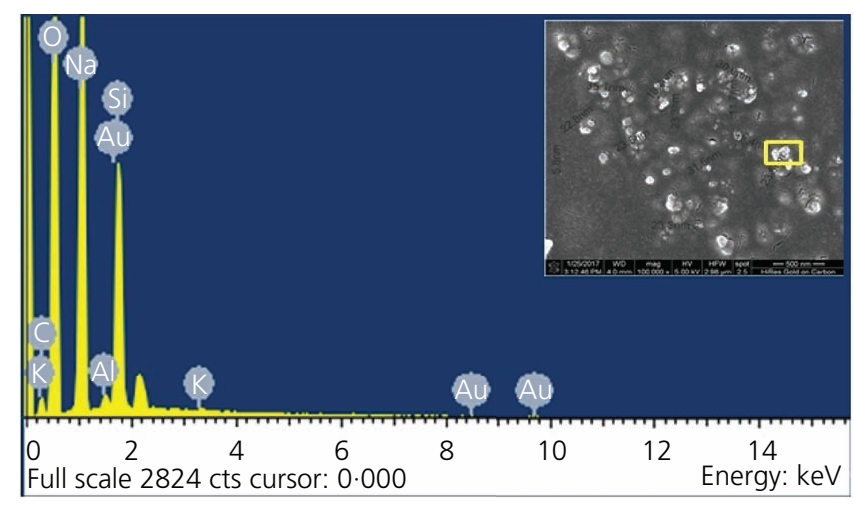

Figure 7. Field emission SEM image and EDX spectrum of novel ML superplasticizer (inset - scanned area for EDX) to those of oxygen and sodium; nevertheless, in the present study, EDX results well supported the XRD results.

To study the detailed microstructure of the ML superplasticizer, SEM micrographs of the sample were acquired at different magnifications and are presented in Figure 8. The presence of mesoporous and microporous inorganic silica is a well-known fact in wood chemistry. Similarly, inorganic silica that had accumulated at the outer surface of rice husk leached into the alkaline solution in the presence of sodium hydroxide and formed sodium silicate. This can be clearly seen in the SEM micrographs of the ML superplasticizer, which indicate the presence of well-uniformed and highly amorphous gel of sodium silicate and strengthen the results obtained by XRD. At different magnifications, the results indicated the porous nature of the ML superplasticizer and showed some unreacted sodium hydroxide along with a vitreous and evenly dispersed silicate framework. Although visual inspections of the organic fractions could not be done at this magnification, the degree of amorphicity and intensified gelation in the ML superplasticizer were probably results of the dispersion of organic groups into the ML superplasticizer, which provided higher slump values for the geopolymer concrete at four increasing dosages. The matrix of the ML superplasticizer was found to be homogenous and contained less pores, and this is consistent with the findings of the compressive strength test (see Figure 3) in terms of drops in strength with the increase in ML superplasticizer dosage.

\section{Concluding remarks}

In this investigation, a novel superplasticizer was developed targeting improvement in the flow behavior of the geopolymer concrete without addition of commercial organic superplasticizers and without compromising the required mechanical strength. Based on the obtained data, it is concluded that the developed ML superplasticizer exhibited an excellent superplasticizing property as indicated by the slump cone test. The flow behavior was increased for all four ML superplasticizer dosages, but correlating with mechanical strength, it is concluded that the most effective dosage of the ML superplasticizer is $0.5 \%$ with respect to fly ash to attain the highest compressive strength along with good workability. However, the visual inspections of all four mixes indicated their much greater workability than the control one, suggesting the suitability of the ML superplasticizer with the geopolymer framework.

From XRD, FTIR and SEM results, it is concluded that the novel ML superplasticizer consists of inorganic phases including sodium silicate, which is synthesized in situ during alkaline digestion of rice husk with sodium hydroxide, and organic phases such as native cellulose, $\beta$-D-fructose and phenol, imparted by rice husk itself as a result of alkaline hydrolysis. Characterization results indicated the presence of organic fractions which functioned as superplasticizers to reduce the viscosity of the geopolymer concrete by neutralizing the charge effects in the geopolymeric skeleton and facilitating easy dispersion of silicon and aluminum into the matrix. This is important as some delay time is needed 

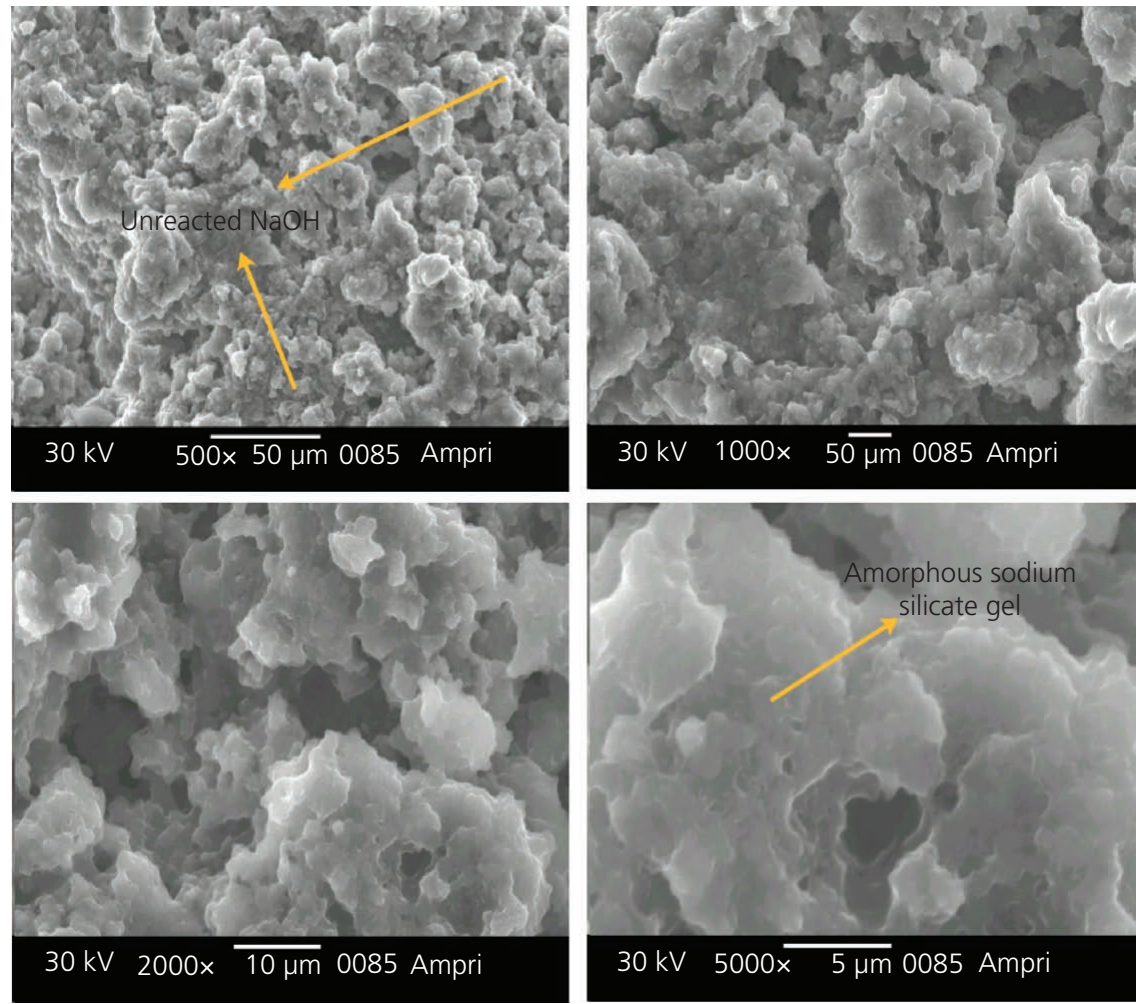

Figure 8. SEM images of novel ML superplasticizer at four different magnifications showing the presence of highly amorphous sodium silicate gel along with unreacted sodium hydroxide

when dealing with the geopolymer concrete due to its highly viscous nature, and it is concluded that by using a $0.5 \%$ novel ML superplasticizer with geopolymer concrete, increased workability and good compressive strength are obtained.

\section{Acknowledgements}

The authors of this paper are highly grateful to the characterization group at CSIR-Ampri for helping in characterization studies for this research work.

\section{REFERENCES}

1. Yeh IC (2007) Modeling slump flow of concrete using second-order regressions and artificial neural networks. Cement and Concrete Composites 29(6): 474-480.

2. Duxson P, Fernandez-Jimenez A, Provis J et al. (2007) Geopolymer technology: the current state of the art. Journal of Materials Science 42(9): 2917-2933.

3. Nematollahi B and Sanjayan J (2014) Effect of different superplasticizers and activator combinations on workability and strength of fly ash based geopolymer. Materials \& Design 57: 667-672.

4. Gupta R, Bhardwaj P, Mishra D, Prasad M and Amritphale SS (2017) Formulation of mechanochemically evolved fly ash based hybrid inorganic-organic geopolymers with multilevel characterization. Journal of Inorganic and Organometallic Polymers and Materials 27(2): 385-398.

5. Chindaprasirt P, Chareerat T and Sirivivatnanon V (2007) Workability and strength of coarse high calcium fly ash geopolymer. Cement and Concrete Composites 29(3): 224-229.
6. Criado MPA, Ferandez JA and Banfill PFG (2009) Alkali activated fly ash: effect of admixtures on paste rheology. Rheologica Acta 48(4): 447-455.

7. Palacios M and Puertas F (2004) Stability of superplasticizers and shrinkage reducing-admixtures in highly basic media. Materiales de Construccion 54(276): 65-86.

8. Bureau of Indian Standards (1959) IS 1199-1959: Indian Standard methods of sampling and analysis of concrete. Bureau of Indian Standards, Manak Bhavan, New Delhi, India.

9. Bureau of Indian Standards (1959) IS 516-1959: Indian Standard methods of tests for strength of concrete. Bureau of Indian Standards, Manak Bhavan, New Delhi, India.

10. Hardjito D, Wallah SE and Rangan BV (2002) Study on engineering properties of fly ash-based geopolymer concrete. Journal of the Australasian Ceramic Society 38(1): 44-47.

11. Teixeira-Pinto A, Fernandes P and Jalali S (2002) Geopolymer manufacture and application - main problems when using concrete technology. Proceedings of the Geopolymers International Conference, Melbourne, Australia.

12. Hardjito D, Wallah SE, Sumajouw DMJ and Rangan BV (2003) Geopolymer concrete: turn waste into environmentally friendly concrete. Proceedings of the International Conference on Recent Trends in Concrete Technology and Structures (INCONTEST), Kumaraguru College of Technology, Coimbatore, India.

13. Hardjito D, Wallah SE, Sumajouw DMJ and Rangan BV (2004) On the development of fly ash-based geopolymer concrete. ACI Materials Journal 101(6): 467-472.

14. Olivia M and Nikraz HR (2012) Properties of fly ash geopolymer concrete designed by Taguchi method. Materials \& Design 36: 191-198.

15. Chang EH (2009) Shear and Bond Behavior of Reinforced Fly Ashbased Geopolymer Concrete Beams. PhD thesis, Faculty of Engineering, Curtin University, Perth, Australia. 
16. Xie J and Obada K (2016) Effect of superplasticizer on workability enhancement of Class F and Class C fly ash-based geopolymers. Construction and Building Materials 122: 36-42.

17. Duxson P, Provis JL, Lukey GC et al. (2005) Understanding the relationship between geopolymer composition, microstructure and mechanical properties. Colloids and Surfaces A: Physicochemical and Engineering Aspects 269(1-3): 47-58.

18. Terinte N, lbbett R and Schuster KC (2011) Overview on native cellulose and microcrystalline cellulose I structure studied by X-ray diffraction (WAXD): comparison between measurement techniques. Lenzinger Berichte 89: 118-131.

19. Neville AM (1996) Properties of Concrete, 4th edn. Prentice Hall, Englewood Cliffs, NJ, USA.

20. Mollah MYA, Adams WJ, Schennach R and Cocke DL (2000) A review of cement-superplasticizer interactions and their models. Advances in Cement Research 12(4): 153-161.

21. Yamada K, Takahashi T, Hanehara S and Matsuhisa M (2000) Effects of the chemical structure on the properties of polycarboxylate-type superplasticizer. Cement and Concrete Research 30(2): 197-207.

22. Panias D and Giannopoulou IP (2006) Development of inorganic polymeric materials based on fired coal fly ash. Acta Metallurgica Slovaca 12(12): 321-327.

23. Adapa PK, Tabil LG, Schoenau GJ, Canam T and Dumonceaux T (2011) Quantitative analysis of lignocellulosic components of nontreated and steam exploded barley, canola, oat and wheat straw using Fourier transform infrared spectroscopy. Journal of Agricultural Science and Technology B 1(12): 177-188.

24. Bhardwaj P, Gupta R, Mishra D, Mudgal M and Amritphale SS (2017) Synthesis of advanced phosphatic geopolymers utilizing fly ash via greener route. Emerging Materials Research 6(1): 168-177.

25. Colthup NB, Daly LH and Wiberley SE (1990) Introduction to Infrared and Raman Spectroscopy, 3rd edn. Academic Press, Boston, MA, USA.

26. Pandey KK (1999) A study of chemical structure of soft and hardwood and wood polymers by FT-IR spectroscopy. Journal of Applied Polymer Science 71: 1969-1975.

\section{How can you contribute?}

To discuss this paper, please submit up to 500 words to the journal office at journals@ice.org.uk. Your contribution will be forwarded to the author(s) for a reply and, if considered appropriate by the editor-in-chief, it will be published as a discussion in a future issue of the journal.

ICE Science journals rely entirely on contributions from the field of materials science and engineering. Information about how to submit your paper online is available at www.icevirtuallibrary.com/page/authors, where you will also find detailed author guidelines. 